\title{
Liver mispuncture during percutaneous endoscopic gastrostomy in a patient with a partial gastrectomy
}

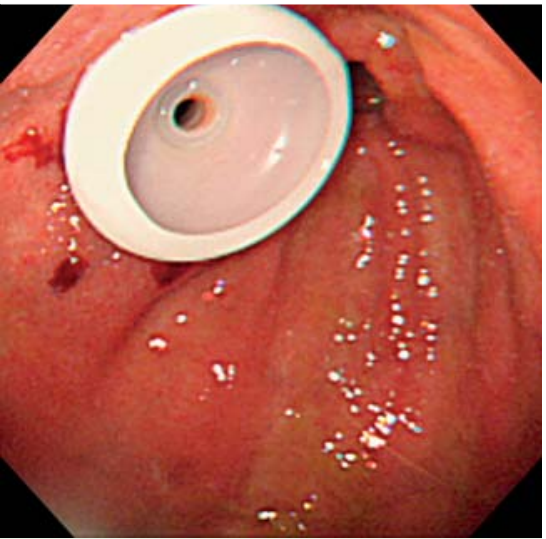

Fig. 1 Endoscopic image showing the bumper of the percutaneous endoscopic gastrostomy (PEG) tube positioned within the stomach.

A 74-year-old man who had undergone partial gastrectomy (Billroth I) for a gastric tumor 15 years previously was admitted to our hospital for post-stroke rehabilitation. Being dysphagic, he was transferred to our hospital with a nasogastric tube; however, long-term tube feeding was deemed necessary and, after careful evaluation, a percutaneous endoscopic gastrostomy (PEG) was performed in an interventional radiology suite with the use of fluoroscopy. A bumper tube-type catheter was inserted using the push technique (Boston Scientific Safety PEG
Kit; Natick, Massachusetts, USA) by puncturing the anterior wall of the remaining stomach just before the anastomotic site (৫ Fig. 1).

Although the procedure ended uneventfully, hematemesis occurred after a few hours. An upper gastrointestinal endoscopy revealed blood oozing from the PEG site with no bleeding lesions within the stomach. An abdominal computed tomography (CT) scan showed the PEG tube had been placed through the lateral segment of the liver ( $\bullet$ Fig. 2 ), confirming a mispuncture during the procedure. The bleeding eventually stopped with the use of antibleeding agents and tightening of the external bolster of the PEG catheter. The patient was transferred to the rehabilitation ward 30 days after the procedure without further complications.

An interposed organ is usually considered an absolute contraindication for a PEG and liver injury (mispuncture) is a rare complication [1]. However, in patients with a previous gastric resection, the remnant stomach is usually overlaid by the transverse colon or the left lobe of the liver, meaning these organs are at risk of injury during PEG insertion. Although in such cases a transhepatic approach to PEG has been suggested to be feasible [2], the risk of postoperative hemorrhage and other complications should be given due con-

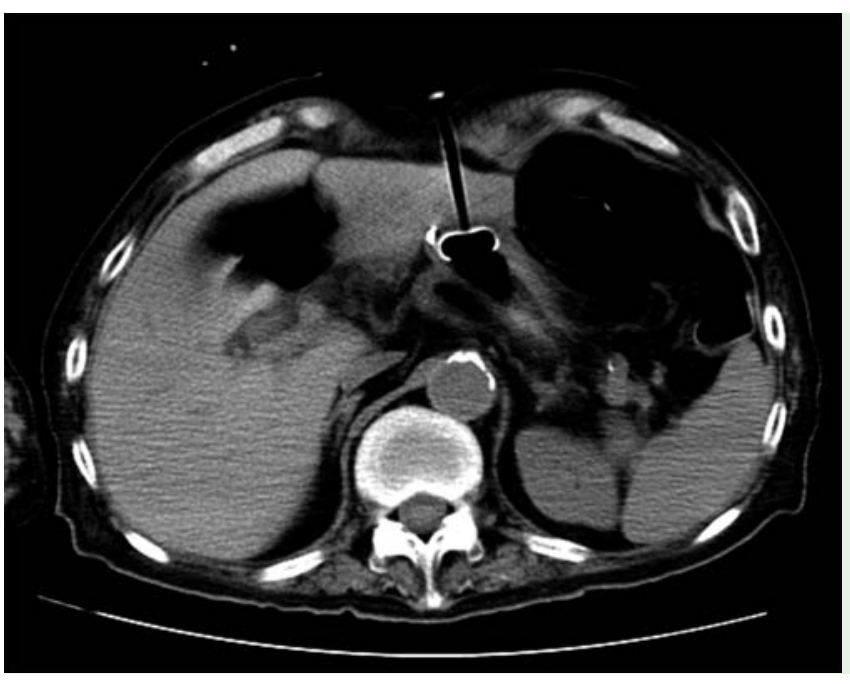

Fig. 2 Computed tomography (CT) scan showing the percutaneous endoscopic gastrostomy (PEG) tube passing through the lateral segment of the liver after a mispuncture during insertion. sideration [3]. When a PEG is not suitable or cannot be performed safely, a minimally invasive esophagostomy procedure, known as percutaneous transesophageal gastro-tubing (PTEG), may be a more appropriate alternative to achieve percutaneous tube feeding without the need for a laparotomy or laparoscopy [4]. Another option would be jejunal feeding using direct percutaneous endoscopic jejunostomy (D-PEJ) [5].

\section{Endoscopy_UCTN_Code_CPL_1AH_2AI}

\section{Competing interests: None}

\section{Ezekiel Wong Toh Yoon, Kazuki Nishihara}

Department of Internal Medicine (Gastroenterology), Hiroshima Kyoritsu Hospital, Hiroshima City, Japan

\section{References}

1 Rahnemai-Azar AA, Rahnemaiazar AA, Naghshizadian $R$ et al. Percutaneous endoscopic gastrostomy: indications, technique, complications and management. World J Gastroenterol 2014; 20: 7739-7751

2 Kanazawa S, Naomoto Y, Hiraki Y et al. Percutaneous feeding gastrostomy in patients with a partial gastrectomy: transhepatic approach with CT guidance. Abdom Imaging 1995; 20: $302-306$

3 Wiggins TF, Kaplan R, Delegge MH. Acute hemorrhage following transhepatic PEG tube placement. Dig Dis Sci 2007; 52: 167-169

4 Oishi $H$, Shindo H, Shirotani $N$ et al. A nonsurgical technique to create an esophagostomy for difficult cases of percutaneous endoscopic gastrostomy. Surg Endosc 2003; 17: 1224-1227

5 Shike M, Schroy P, Ritchie MA et al. Percutaneous endoscopic jejunostomy in cancer patients with previous gastric resection. Gastrointest Endosc 1987; 33: 372 - 374

\section{Bibliography}

DOI http://dx.doi.org/

10.1055/s-0042-106967

Endoscopy 2016; 48: E182

(C) Georg Thieme Verlag KG

Stuttgart · New York

ISSN 0013-726X

\section{Corresponding author}

\section{Ezekiel Wong Toh Yoon, MD}

Department of Internal Medicine

Hiroshima Kyoritsu Hospital

2-20-20 Nakasu Asaminami-ku Hiroshima City

Japan

easybs@hotmail.com 